\title{
Optical and Thermal Properties of Zn/Al-Layered Double Hydroxide Nanocomposite Intercalated with Sodium Dodecyl Sulfate
}

\author{
Samaneh Babakhani, ${ }^{1}$ Zainal Abidin Talib, ${ }^{1}$ \\ Mohd Zobir Hussein, ${ }^{2}$ and Abdullah Ahmed Ali Ahmed ${ }^{3}$ \\ ${ }^{1}$ Department of Physics, Faculty of Science, Universiti Putra Malaysia (UPM), 43400 Serdang, Selangor, Malaysia \\ ${ }^{2}$ Advanced Materials and Nanotechnology Laboratory, Institute of Advanced Technology (ITMA), Universiti Putra Malaysia (UPM), \\ 43400 Serdang, Selangor, Malaysia \\ ${ }^{3}$ Department of Physics, Faculty of Applied Science, Thamar University, P.O. Box 87246, Thamar, Yemen
}

Correspondence should be addressed to Zainal Abidin Talib; zainalat@upm.edu.my

Received 16 July 2014; Accepted 4 October 2014; Published 28 October 2014

Academic Editor: Rizwan Hasan Khan

Copyright (C) 2014 Samaneh Babakhani et al. This is an open access article distributed under the Creative Commons Attribution License, which permits unrestricted use, distribution, and reproduction in any medium, provided the original work is properly cited.

$\mathrm{Zn} / \mathrm{Al}-\mathrm{LDH}-\mathrm{SDS}$ nanocomposites have been prepared using a coprecipitation method in different molar ratio of $\mathrm{Zn}^{2+} / \mathrm{Al}^{3+}=2$, 3 , and 4 at $\mathrm{pH}=10$ and different concentrations of sodium dodecyl sulfate solution $(0.2 \mathrm{M}, 0.4 \mathrm{M}$, and $0.8 \mathrm{M})$. The XRD and FTIR data show the successful intercalation of SDS into the LDH interlayer. The XRD diffractogram showed that the basal spacing for $\mathrm{Zn} / \mathrm{Al}-\mathrm{NO}_{3}{ }^{-}$is $0.89 \mathrm{~nm}$ compared to $2.54-2.61 \mathrm{~nm}$ for the $\mathrm{Zn} / \mathrm{Al}$-SDS nanocomposite. Optical band gap of the samples was calculated using Kubelka-Munk model. Due to the presence of LDH phase, two band gap energies $\left(E_{g 1}\right.$ and $\left.E_{g 2}\right)$ were observed. The values of $E_{g 1}$ and $E_{g 2}$ were found around $4.8 \mathrm{eV}$ and $3.75 \mathrm{eV}$ for $\mathrm{Zn} / \mathrm{Al}-\mathrm{LDH}(r=2,3$, and 4). The values of band gap of LDH-SDS nanocomposites were found to increase to around $4.2 \mathrm{eV}$ and $5.2 \mathrm{eV}$. For Zn4Al-LDH-SDS with $0.4 \mathrm{M}$ and $0.8 \mathrm{M}$ of SDS, only one energy gap at around $3.23 \mathrm{eV}$ was observed. The optical band gap of $\mathrm{SO}_{4}{ }^{2-}$ phase increased as the amount of SDS increases. Thermal diffusivity of the resulted nanocomposite was also investigated.

\section{Introduction}

One ideal host for the organic-inorganic nanohybrid materials or nanocomposites can be a two-dimensional layered structure that includes thin crystalline inorganic layers that have a molecular scale thickness of a nanometer range. Layered double hydroxide (LDH) can be named as an example for this structure. Planting various anionic species as guests inside interlayer spaces of the LDH leads to having a growth in the interlayer distance toward a nanometer size dimension that shapes a new nanohybrid material [1]. LDHs are currently under spotlight because of their capabilities in industrial and medical applications. They have a key role in the fields of separation process, catalysis, DNA or biomolecule carriers, and drug delivery (controlled drug release). In addition to their role as working nanostructures, they also put on show a large number of electronic and magnetic properties.

Since organic-inorganic hybrid materials have improved and better properties rather than their counterparts, development of these types of materials provides excellence aspects of applications in different areas of technology and science. This also is because their property can be tailor-made to special application such as photochromic coating, photochemical reaction, and selective optical transmission, to name a few. For the formation of a nanolayered composite of organicinorganic hybrid type or the so-called nanocomposite materials, LDHs or hydrotalcite-like material can be one of the popular inorganic hosts for the formation of an organicinorganic hybrid type. Several studies have focused on intercalation of various dye molecules, especially organic dyes, 


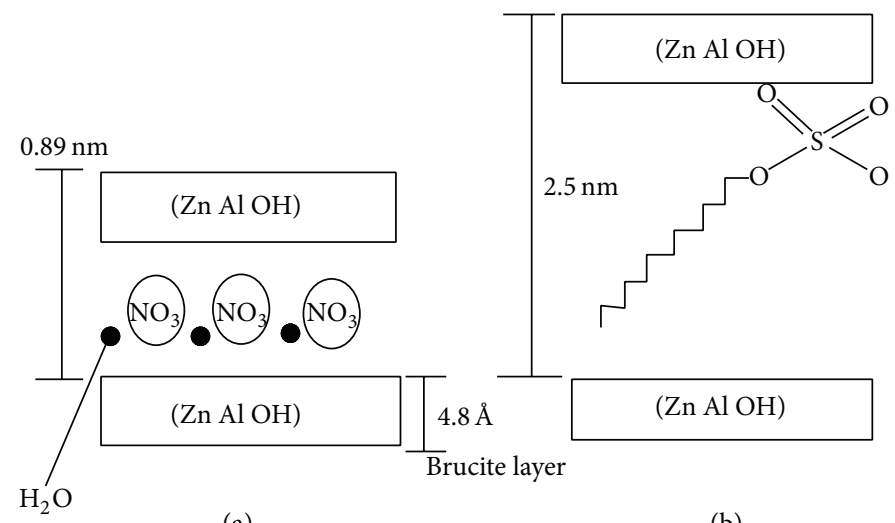

(a)

(b)

FIGURE 1: Schematic figure of (a) LDH and (b) LDH-SDS.

into the layered inorganic lamella, in particular anionic clays for different applications and purposes [2].

Considering the above findings, an idea to study the properties of novel nanocomposites with intercalated anion has been generated. Sodium dodecyl sulfate has been specially chosen to study the physical properties of the obtained nanocomposite. We report here the synthesis of $\mathrm{Zn} / \mathrm{Al}-\mathrm{LDH}$ by coprecipitation method, intercalation of Sodium dodecyl sulfate into the interlayer of the LDHs, a comparative study of the UV absorption ability of the LDH-SDS nanocomposites, thermal diffusivity of the resulted nanocomposites, and the effect of intercalation on the morphology.

\section{Experimental}

2.1. Materials. The metal nitrates of aluminum nitrate $\mathrm{Al}\left(\mathrm{NO}_{3}\right)_{3} \cdot 9 \mathrm{H}_{2} \mathrm{O}$ (Hamburg Chemicals Co., 99.4\%), zinc nitrate $\mathrm{Zn}\left(\mathrm{NO}_{3}\right)_{2} \cdot 6 \mathrm{H}_{2} \mathrm{O}$ (System, 98\%), and $\mathrm{NaOH}$ (Merck Co., 99\%) were used without further purification. Sodium dodecyl sulfate (SDS) (Merck Co., 98\%) was used as the organic compound for the intercalation process. The solvent used throughout this study was deionized water.

\subsection{Synthesis of $\mathrm{Zn} / \mathrm{Al}-\mathrm{NO}_{3}$ Hydrotalcite and $\mathrm{Zn} / \mathrm{Al}$-Sodium} Dodecyl Sulfate Nanocomposite. $\mathrm{Zn} / \mathrm{Al}-\mathrm{NO}_{3}{ }^{-} \mathrm{LDH}$ precursor was synthesized using coprecipitation method with a molar ratio of $\mathrm{Zn}^{2+} / \mathrm{Al}^{3+}, r=2,3$, and 4 . The slow mixing of metal nitrates solution of $\mathrm{Al}\left(\mathrm{NO}_{3}\right)_{3} \cdot 9 \mathrm{H}_{2} \mathrm{O}$ and $\mathrm{Zn}\left(\mathrm{NO}_{3}\right)_{2} \cdot 6 \mathrm{H}_{2} \mathrm{O}$ was carried out under constant stirring. The titration process was done by dropwise addition of aqueous $\mathrm{NaOH}(1.0 \mathrm{M})$ until $\mathrm{pH}=10$. In order to avoid the contamination of $\mathrm{CO}_{2}$ from the atmosphere or at least to minimize it, the titration of $\mathrm{NaOH}$ was carried out under a constant flow of $\mathrm{N}_{2}$ gas. For the next step, the resulting slurry was placed in an oil bath shaker $(70 \mathrm{rpm})$ for $18 \mathrm{~h}$ and aged at $70^{\circ} \mathrm{C}$. The precipitate was centrifuged and washed with deionized water many times and dried in an oven at $70^{\circ} \mathrm{C}$ for 2 days. After grinding the resulting nanocomposite into a fine powder, it was stored in sample bottles and labeled as $\mathrm{Zn} r \mathrm{Al}-\mathrm{LDH}$ for further use ( $r$ represents the molar ratio). To produce LDH with SDS, before the titration with $\mathrm{NaOH}$, the desired amount of sodium dodecyl sulfate was added into a solution containing $\mathrm{Zn}\left(\mathrm{NO}_{3}\right)_{2} \cdot 6 \mathrm{H}_{2} \mathrm{O}$ and $\mathrm{Al}\left(\mathrm{NO}_{3}\right)_{3} \cdot 9 \mathrm{H}_{2} \mathrm{O}$. A $50 \mathrm{~mL}$ of solution containing $0.2 \mathrm{M}, 0.4 \mathrm{M}$, and $0.8 \mathrm{M}$ of SDS was added to a $100 \mathrm{~mL}$ of $\mathrm{Zn} / \mathrm{Al}$ solution. The dropwise addition of $\mathrm{NaOH}$ was continued until the $\mathrm{pH}$ of the solution reached $\mathrm{pH}$ 10. The samples were ground into a fine powder, stored in sample bottles, and labeled as $\mathrm{Zn} r \mathrm{Al}-\mathrm{LDH}-\mathrm{SDS}$ for further use.

2.3. Characterization. Powder X-ray diffraction (PXRD) patterns of the samples were recorded on a diffractometer (X'PERT-PROPANALYTICAL) using CuK $\alpha(1.54187 \AA)$ at $40 \mathrm{kV}$ and $30 \mathrm{~mA}$. The FTIR spectra were obtained using a Thermo Nicolet NEXUS FTIR spectrophotometer (model: SMART ORBIT) in the range of $400-4000 \mathrm{~cm}^{-1}$. The powdered samples were ground with $\mathrm{KBr}$ in 1:20 ratio and pressed into pellets for recording the spectra. The band gap was calculated using the optical measurements that were performed on a UV-VIS-NIR diffuse reflectance spectrophotometer (Shimadzu, UV-3600). Thermal diffusivity measurements were performed using NETZSCH, model LFA 457 MicroFlash. The surface morphologies of the samples were observed by a field emission scanning electron microscope (FESEM), model NOVA NANOSEM 230.

\section{Results and Discussion}

3.1. Powder X-Ray Diffraction (XRD) Study. SDS (sodium dodecyl sulfate) intercalated $\mathrm{Zn} / \mathrm{Al}-\mathrm{LDH}$ nanocomposites were prepared using precipitation method. Figure 2 shows that the powder XRD patterns of the $\mathrm{Zn} / \mathrm{Al}-\mathrm{NO}_{3}$ and SDS intercalated LDHs synthesized in different concentration of SDS. The sharpness of the peaks suggests ordered and regular stacking of the LDH layers. XRD of the $\mathrm{Zn} r \mathrm{Al}-\mathrm{NO}_{3}-\mathrm{LDH}$ samples (Figure $1(\mathrm{~d})$ ) for $r=2$ and 3 displays (003), (006), (009), (101), (110), and (113) crystal planes [3] with the basal spacing of $0.890 \mathrm{~nm}$ for (003), while for ratio $4 \mathrm{a}$ new phase formed with different reflections for planes (003) (Figure 2(d)). This phase can be attributed to the presence of $\mathrm{Zn} / \mathrm{Al}-\mathrm{CO}_{3}-\mathrm{LDH}$ within prepared sample at ratio $4 . \mathrm{A} \mathrm{CO}_{2}$ capture process from air based on the carbonation of $\mathrm{NaOH}$ aqueous solution has been estimated [4]. The FTIR spectra further confirm the presence of $\mathrm{CO}_{3}{ }^{-}$for $\mathrm{LDH}$ sample at 


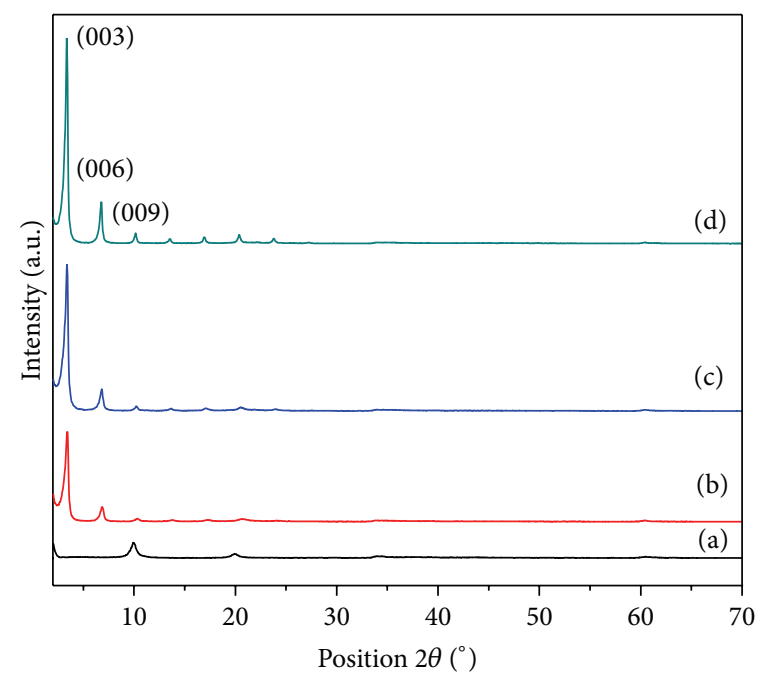

(d) Zn2Al-LDH-SDS $0.8 \mathrm{M}$ (c) Zn2Al-LDH-SDS $0.4 \mathrm{M}$

(a)

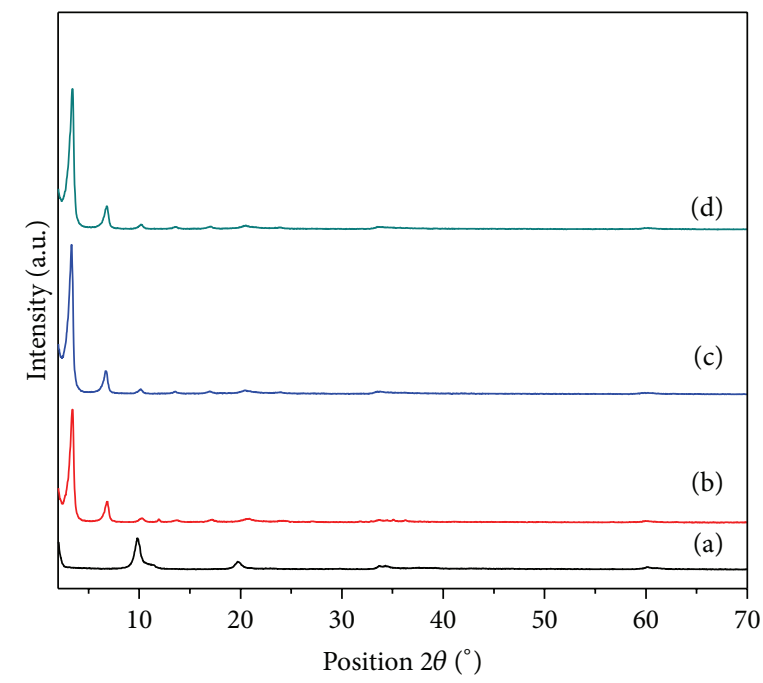

(d) Zn4Al-LDH-SDS $0.8 \mathrm{M}$ - (b) Zn4Al-LDH-SDS $0.2 \mathrm{M}$

(c) Zn4Al-LDH-SDS 0.4 M - (a) Zn4Al-LDH

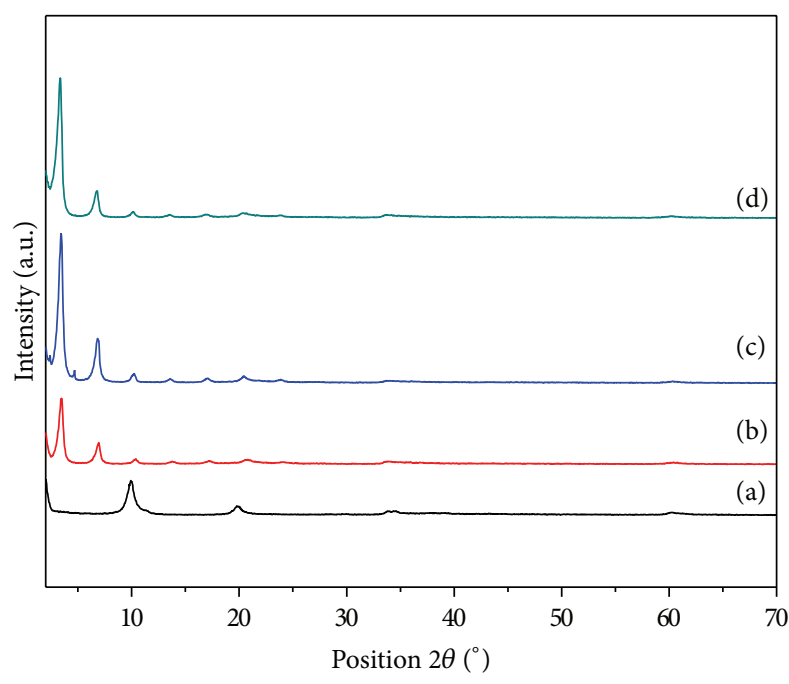

(d) Zn3Al-LDH-SDS $0.8 \mathrm{M}$

(b) Zn3Al-LDH-SDS 0.2 M (c) Zn3Al-LDH-SDS $0.4 \mathrm{M}-$ (a) Zn3Al-LDH

(b)

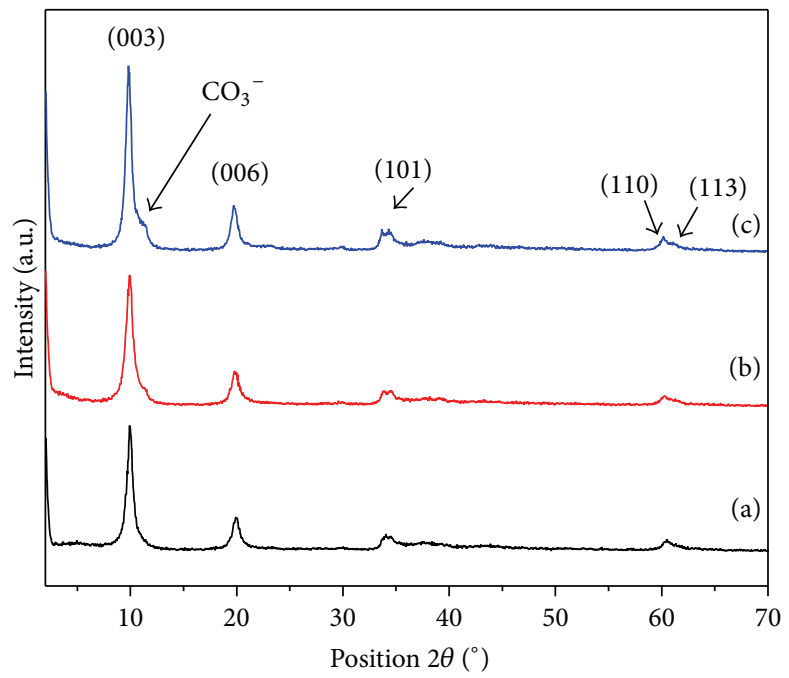

- (c) Zn4Al-LDH

- (b) Zn3Al-LDH

- (a) Zn2Al-LDH

(c)

(d)

FIGURE 2: Powder XRD patterns of Zn $r$ Al-LDH and LDH-SDS with different SDS concentrations at (a) $r=2$, (b) $r=3$, (c) $r=4$, and (d) $\mathrm{Zn} / \mathrm{Al}-\mathrm{LDH}$ at ratios 2,3 , and 4 .

ratio 4. Basal spacing is equal to the thickness of one brucitelike layer $(4.8 \AA)$ plus one interlayer which accounts for the interlayer gallery distance and can be calculated from Bragg's equation.

By intercalation of SDS into the LDH interlayer, SDS can increase the layer thickness considering its large molecular weight as seen in Figure 1. As expected, the (003), (006), and (009) crystal planes [5] were observed in XRD patterns of the SDS intercalated samples as shown in Figure 2. The appearance of higher order peaks as well as the characteristic intense basal reflection peaks gives evidence of highly oriented in $c$-direction of intercalated LDH structure for all samples. SDS intercalation within the galleries was indicated from the shifting in the basal spacing. The basal spacing $d_{003}$ shifted from $0.89 \mathrm{~nm}$ for $\mathrm{Zn} 4 \mathrm{Al}-\mathrm{NO}_{3}-\mathrm{LDH}$ to $2.555 \mathrm{~nm}$, $2.617 \mathrm{~nm}$, and $2.560 \mathrm{~nm}$ for LDH-SDS with $0.2 \mathrm{M}, 0.4 \mathrm{M}$, and $0.8 \mathrm{M}$ of SDS, respectively. Similar basal spacing values were reported for LDH-SDS prepared by other methods [6]. The increasing of PXRD intensity of the LDH and LDH-SDS peaks was observed as the $\mathrm{Zn}^{2+} / \mathrm{Al}^{3+}$ molar ratio and the SDS concentration increases.

The indexing of PXRD indicating the lattice parameters $a$, $c$, and $c^{\prime}$ for ZnrAl-LDH and LDH-SDS samples is shown in Table 1. Averaging the positions of the three harmonics can 


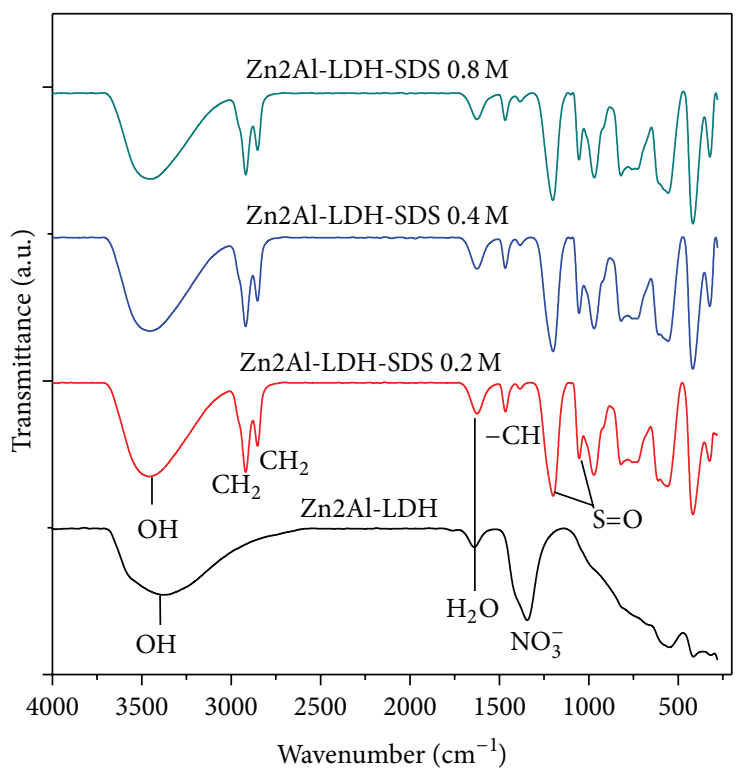

(a)

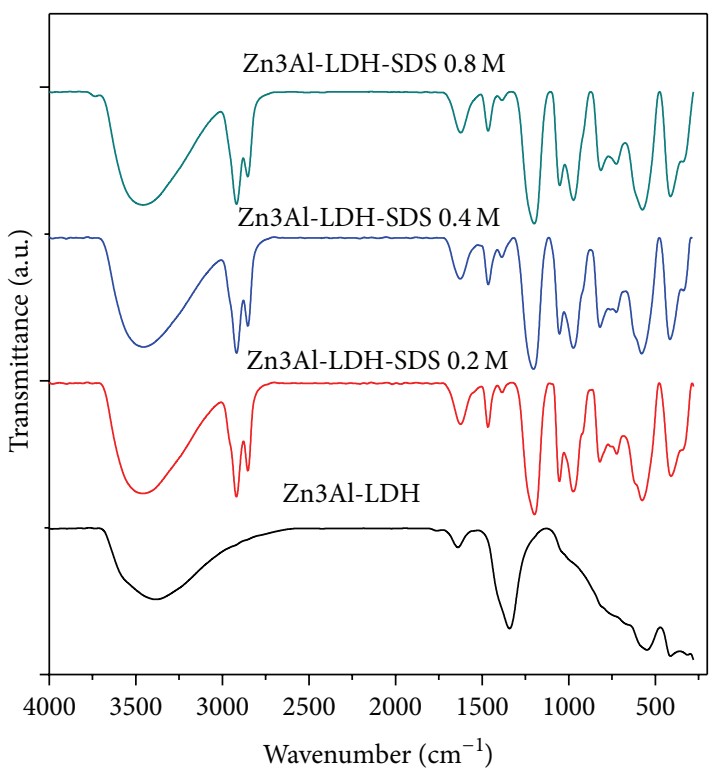

(b)

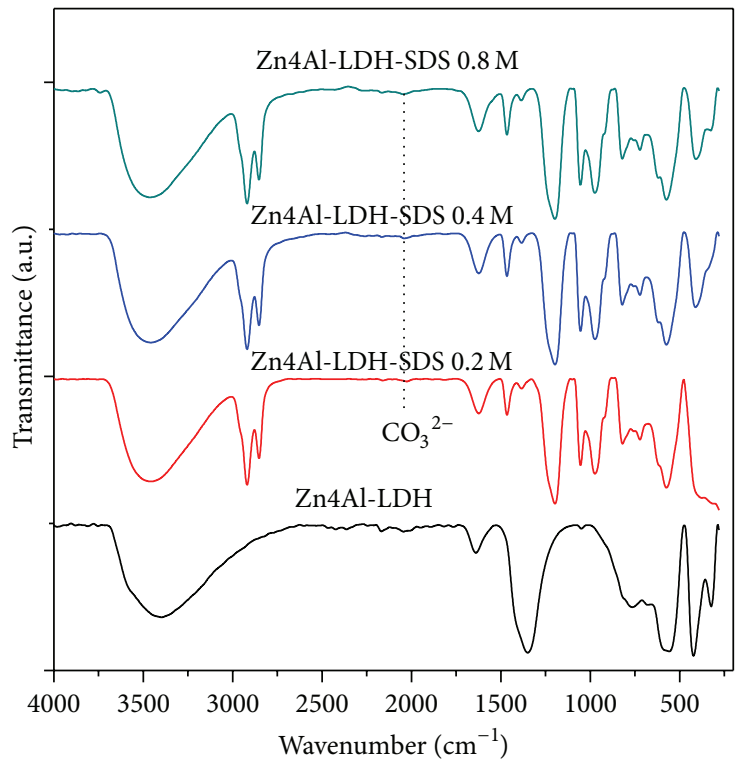

(c)

FIGURE 3: FT-IR spectra of ZnrAl-LDH and LDH-SDS with different concentrations of SDS at (a) $r=2$, (b) $r=3$, and (c) $r=4$.

be used to calculate the interlayer spacing: $c=(1 / 3)\left(3 d_{003}\right.$ $\left.+6 d_{006}+9 d_{009}\right), a=2 d_{110}$ and $c=3 c^{\prime}$ [3]. Accepting the full length of SDS molecules as $2.08 \mathrm{~nm}$, SDS molecules should form a tilted interdigitated bilayer between the $\mathrm{Zn} / \mathrm{Al}$ sheets. The FT-IR spectra can further confirm the successful cointercalation of the SDS anions as shown in Figure 3.

3.2. Fourier Transform Infrared (FTIR). Figure 3 shows the FT-IR spectra of $\mathrm{ZnrAl}-\mathrm{NO}_{3}-\mathrm{LDH}$ and $\mathrm{LDH}-\mathrm{SDS}$ in different concentration of SDS and at different molar ratio of $\mathrm{Zn} / \mathrm{Al}$. The FTIR spectra of the $\mathrm{LDH}$ precursor indicate a broad band at around $3398 \mathrm{~cm}^{-1}$. This band is attributed to the $\mathrm{O}-\mathrm{H}$ stretching vibration in the brucite-like layers and the interlamellar water molecules [7] while the broadening of the band is assigned to formation of hydrogen bond [8]. The appearance of the strong absorption band located at $1387 \mathrm{~cm}^{-1}$ is attributed to the $v_{3}$ stretching vibration of the $\mathrm{NO}_{3}{ }^{-}$groups in the $\mathrm{LDH}$ interlayer [9]. The sharpness of this peak of sample ratio 4 is lower than that in the other samples which may indicate the presence of $\mathrm{Zn} / \mathrm{Al}-\mathrm{CO}_{3}-\mathrm{LDH}$ phase [3]. A weak band located at $764 \mathrm{~cm}^{-1}$ and $1765 \mathrm{~cm}^{-1}$ arises from the stretching modes which confirm the presence of nitrate group, the intergallery anion with $D_{3 h}$ symmetry in the $\mathrm{Zn} / \mathrm{Al} \mathrm{LDH}$ interlayer [9]. The bending vibration of the interlayer water molecules is indicated with the band at $1639 \mathrm{~cm}^{-1}$ [7].

The appearance of the bands at around $414 \mathrm{~cm}^{-1}$ and $557 \mathrm{~cm}^{-1}$ is attributed to $\mathrm{O}-\mathrm{M}-\mathrm{O}$ vibrations in the 


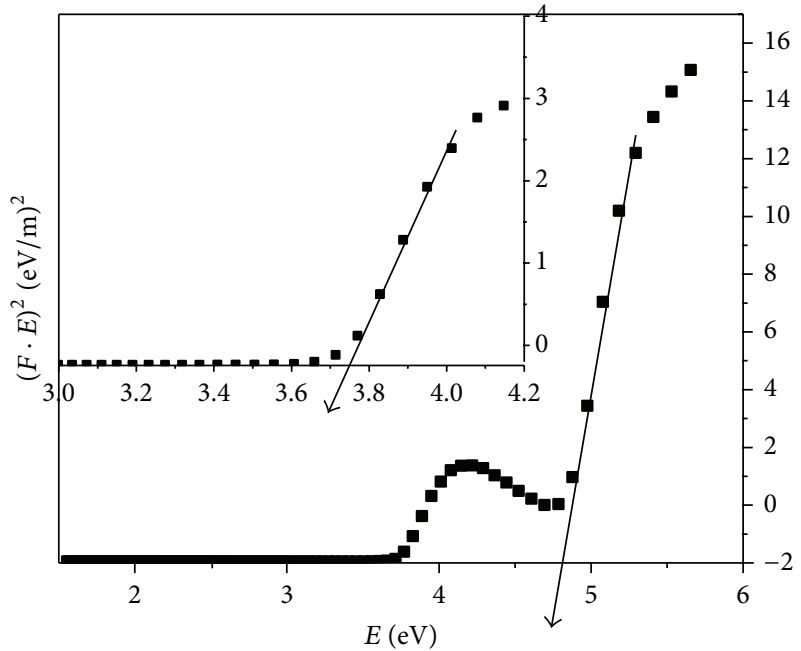

- Zn3Al-LDH

(a)

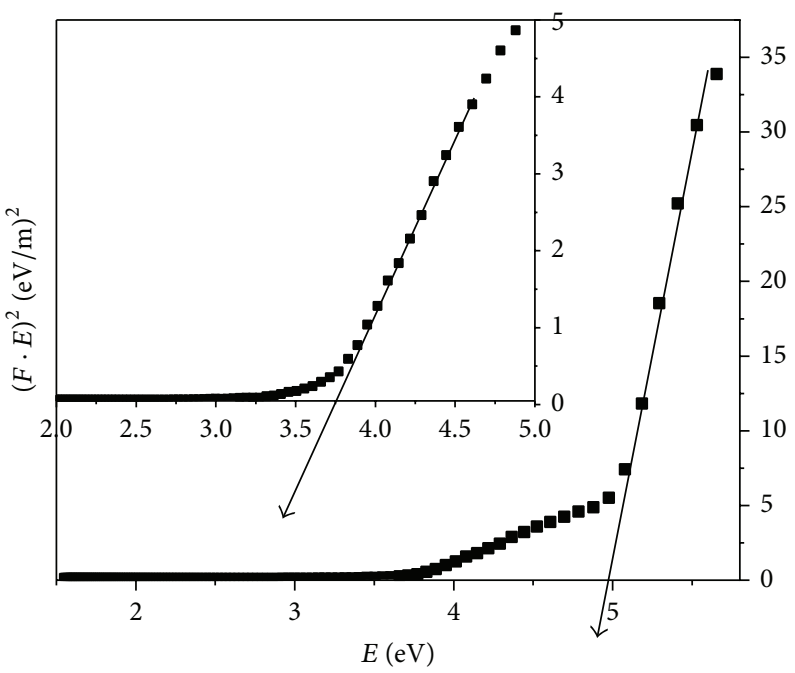

- Zn3Al-LDH-SDS 0.4 M

(c)

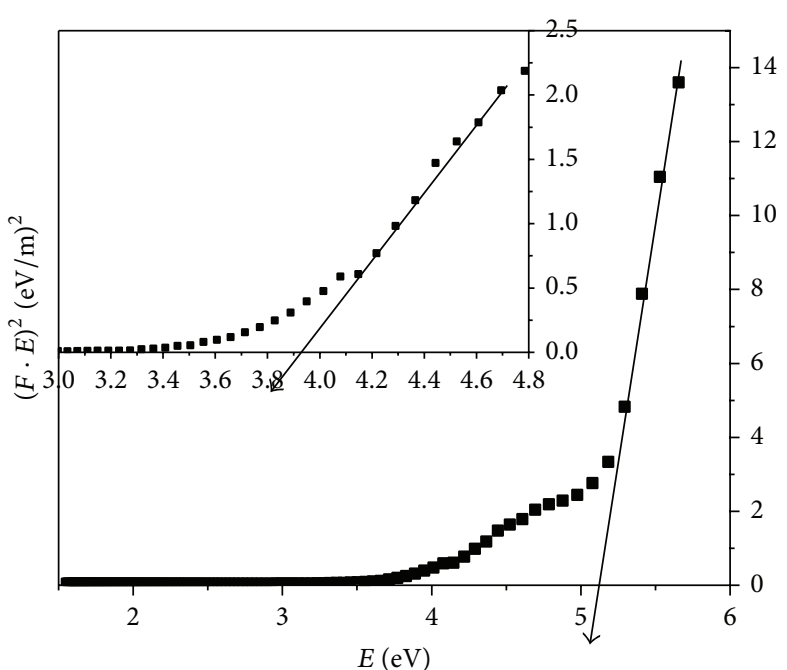

- Zn3Al-LDH-SDS $0.2 \mathrm{M}$

(b)

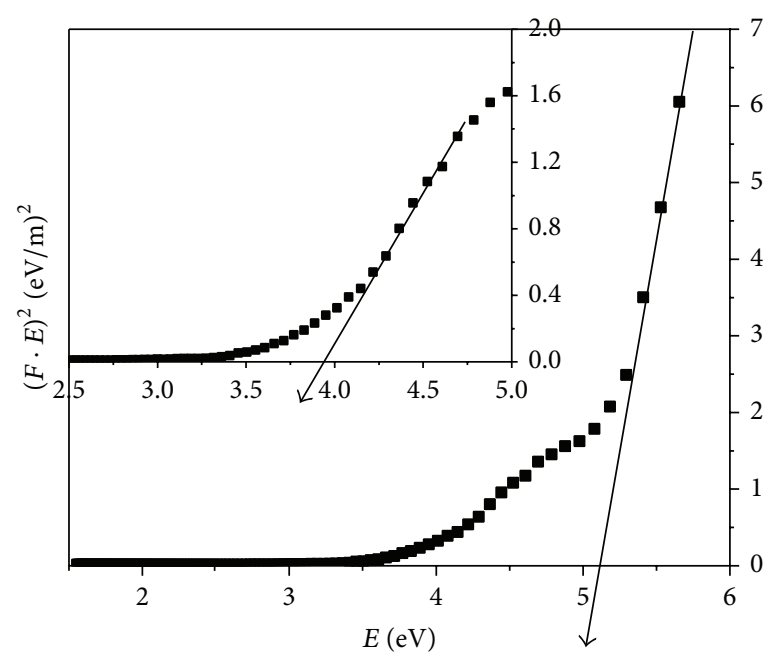

- Zn3Al-LDH-SDS $0.8 \mathrm{M}$

(d)

FIGURE 4: Kubelka-Munk transformed reflectance spectra of $\mathrm{Zn} 3 \mathrm{Al}-\mathrm{NO}_{3}-\mathrm{LDH}$ and $\mathrm{LDH}-\mathrm{SDS}$ in different concentrations.

brucite-like layers [10] and the lattice vibration modes corresponding to the translation vibration of $\mathrm{Zn}-\mathrm{OH}$ [7], respectively. The relative intensity of band at 422 is clearly high for molar ratio of 4 , but at ratio 2 and 3 it starts to decrease. This may suggest that the $\mathrm{M}-\mathrm{O}$ vibrations of the $\mathrm{LDH}$ layers decreased due to the formation of new phases $\left(\mathrm{CO}_{3}{ }^{2-}\right)$.

The FT-IR spectra of LDH-SDS were shown in Figure 3. The wide band was found at $3464 \mathrm{~cm}^{-1}$ and it is attributed to the $\mathrm{OH}$ mode which is due to the hydroxyl groups and the interlayer water molecules in the brucite-like layers. The vibrations at 1197 and $1054 \mathrm{~cm}^{-1}$ are attributed to the $\mathrm{OSO}_{3}{ }^{-}$asymmetric and symmetric stretching vibration of the sulfonate group while the characteristic absorption peaks at 2919 and $2852 \mathrm{~cm}^{-1}$ arise from the asymmetric $\left(\mathrm{CH}_{2}\right)$ and symmetric $\left(\mathrm{CH}_{2}\right)$ vibration bands of SDS [11] (the observation of bands at around $1000-1370 \mathrm{~cm}^{-1}$ can imply the presence of $\mathrm{SO}_{3}{ }^{-}$group). The weak band observed at $1624 \mathrm{~cm}^{-1}$ is assigned to $\mathrm{H}_{2} \mathrm{O}$ from the interlayer water [12].

The surfactant (SDS) displays two prominent vibrations at $2919 \mathrm{~cm}^{-1}$ and $2852 \mathrm{~cm}^{-1}$, corresponding to the symmetric and antisymmetric $\mathrm{C}-\mathrm{H}$ - stretching modes of the terminal $-\mathrm{CH}_{3}$ groups and a $\mathrm{C}-\mathrm{H}$ bending vibration band at $1465 \mathrm{~cm}^{-1}$. The bands observed at around $414 \mathrm{~cm}^{-1}$ and $557 \mathrm{~cm}^{-1}$ for LDH samples were found at around $417 \mathrm{~cm}^{-1}$ (it was observed for all samples except Zn2Al-LDH-SDS $0.2 \mathrm{M}$ ) and $574 \mathrm{~cm}^{-1}$, respectively, for LDH-SDS samples which are assigned to the lattice vibrations of the metal hydroxide sheets [13]. The nitrate ion vibration mode at $1387 \mathrm{~cm}^{-1}$ disappears in SDS-LDH which is due to the ion exchange process and 


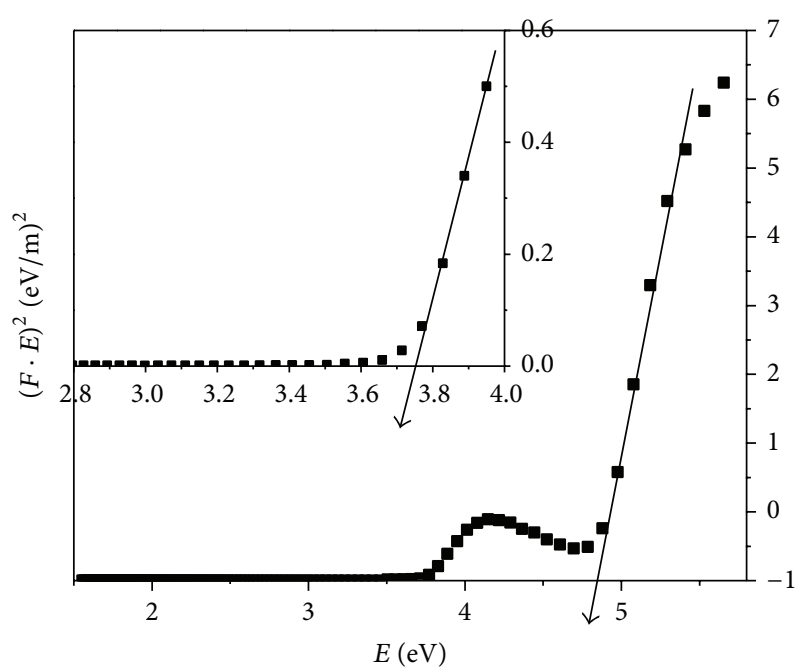

- Zn4Al-LDH

(a)

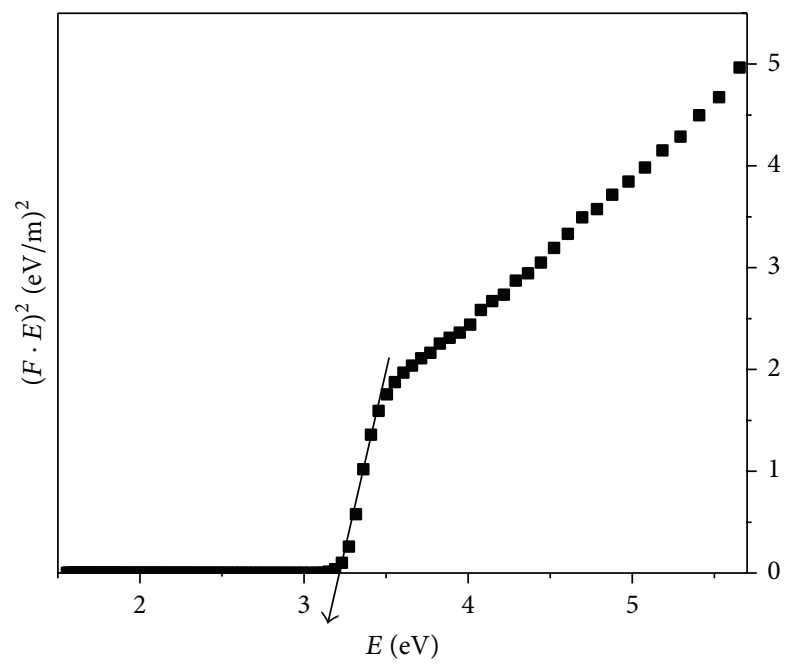

- Zn4Al-LDH-SDS $0.4 \mathrm{M}$

(c)

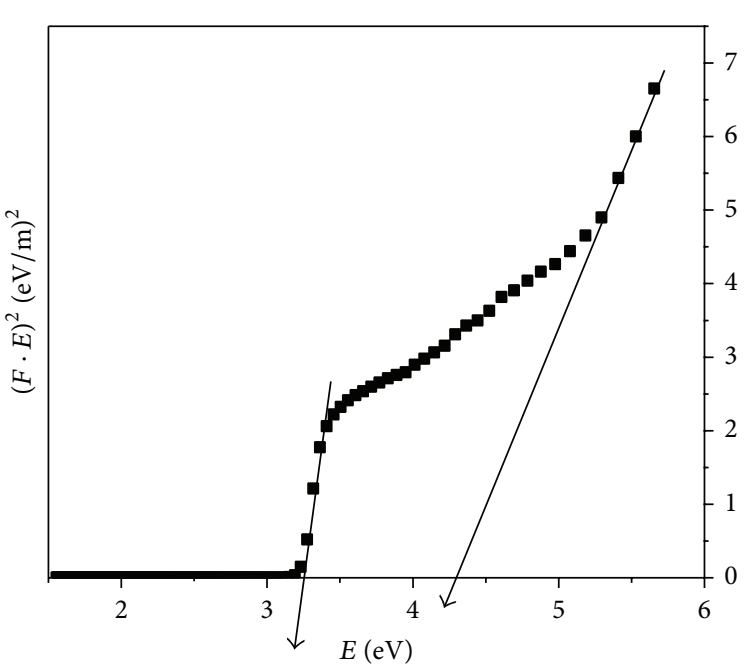

- Zn4Al-LDH-SDS $0.2 \mathrm{M}$

(b)

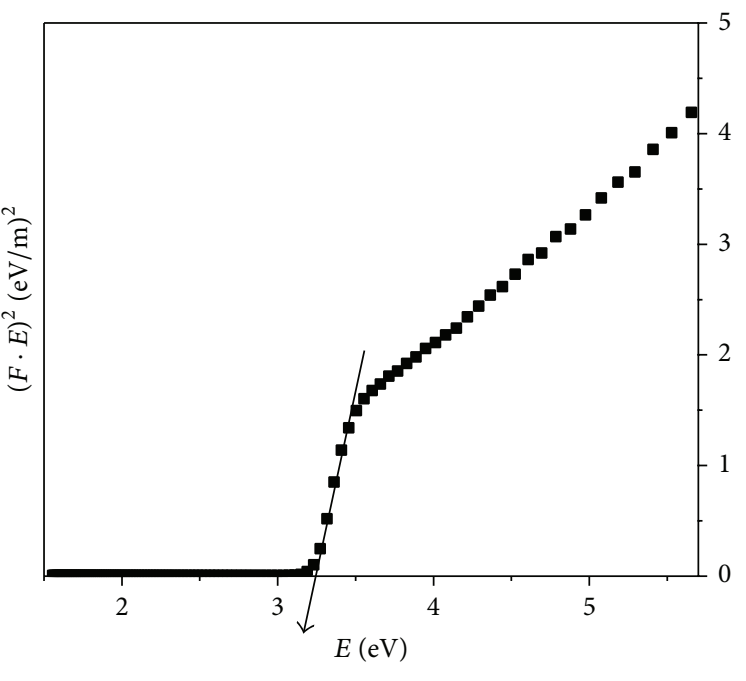

- Zn4Al-LDH-SDS $0.8 \mathrm{M}$

(d)

FIGURE 5: Kubelka-Munk transformed reflectance spectra of $\mathrm{Zn} 4 \mathrm{Al}-\mathrm{NO}_{3}-\mathrm{LDH}$ and LDH-SDS in different concentrations.

thus suggests that the SDS can completely replace the nitrate anions in the LDH interlayer. It is noteworthy that the extra weak band at around $2040 \mathrm{~cm}^{-1}$ is observed for samples with ratio 4 which can be assigned to adsorbed $\mathrm{CO}_{3}{ }^{2-}$ species [14].

3.3. Optical Properties (UV-VIS-NIR). UV-VIS-NIR diffuse reflectance spectra by using the Kubelka-Munk equation shown below were used to obtain the energy gap [15]:

$$
\begin{gathered}
F\left(R_{\infty}\right)=\frac{(1-R)^{2}}{2 R_{\infty}}, \\
\left(F\left(R_{\infty}\right) h v\right)^{2}=C\left(h v-E_{g}\right),
\end{gathered}
$$

where $F\left(R_{\infty}\right)$ is called Kubelka-Munk function or the remission and the diffuse reflectance $\left(R_{\infty}\right)$ of the samples is
$R_{\infty}=R_{\text {sample }} / R_{\text {standard }}[16], h v$ is the photon energy, and $C$ is a proportionality constant. The energy gap of $\mathrm{Zn} / \mathrm{Al}-\mathrm{LDH}$ can be obtained based on the Kubelka-Munk model according to (2). The $F\left(R_{\infty}\right)$ from (1) was plotted as $\left(F\left(R_{\infty}\right) h v\right)^{2}$ against $h v$, from which the energy gap $\left(E_{g}\right)$ of the samples can be easily extracted.

The energy gaps of $\mathrm{Zn} r \mathrm{Al}-\mathrm{NO}_{3}-\mathrm{LDH}$ and LDH-SDS in different concentrations were investigated by these measurements and are shown in Figures 4 and 5. Figure 4 shows the energy gap $\left(E_{g}\right)$ of $\mathrm{Zn} 3 \mathrm{Al}-\mathrm{NO}_{3}-\mathrm{LDH}$ and LDH-SDS in different concentrations. Due to the presence of $\mathrm{LDH}$ phase, two band gap energies $\left(E_{q 1}\right.$ and $\left.E_{q 2}\right)$ were observed. The first band gap $\left(E_{g 1}\right)$ for $\mathrm{Zn} r \mathrm{Al}-\mathrm{NO}_{3}-\mathrm{LDH}$ is 4.8 and $4.75 \mathrm{eV}$ for $r=2$ and 3 , respectively. The second one $\left(E_{g 2}\right)$ is $3.75 \mathrm{eV}$ for $r=2$ and $3.72 \mathrm{eV}$ for $r=3$. All values of band gap energy for 

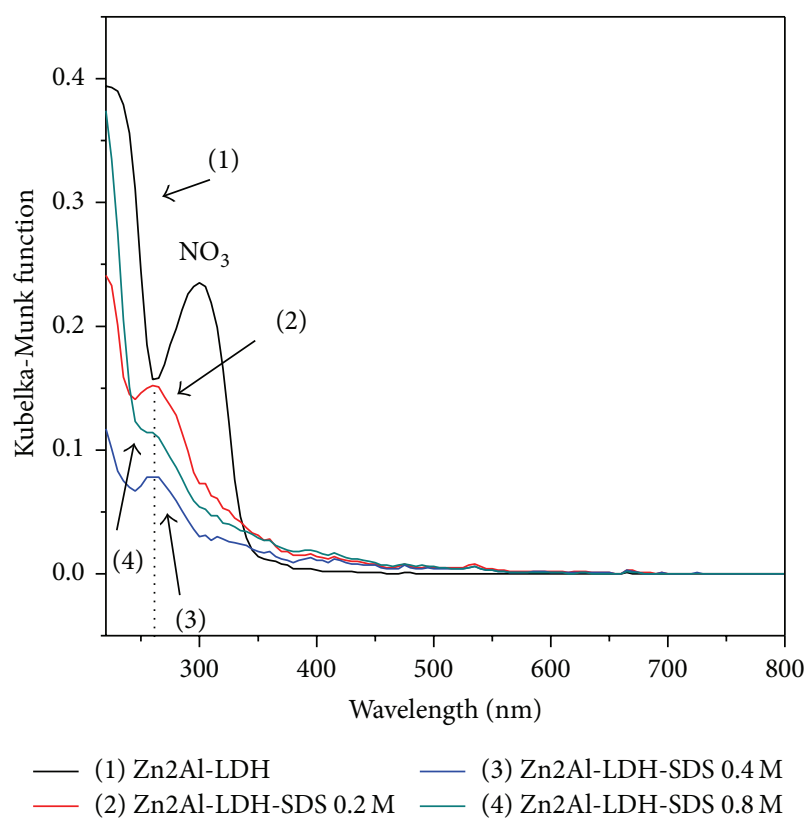

(a)

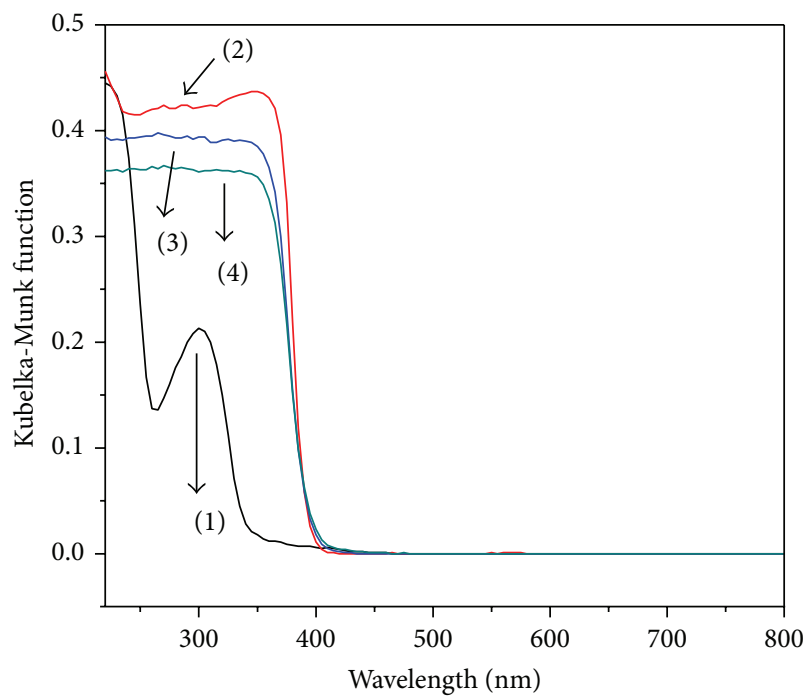

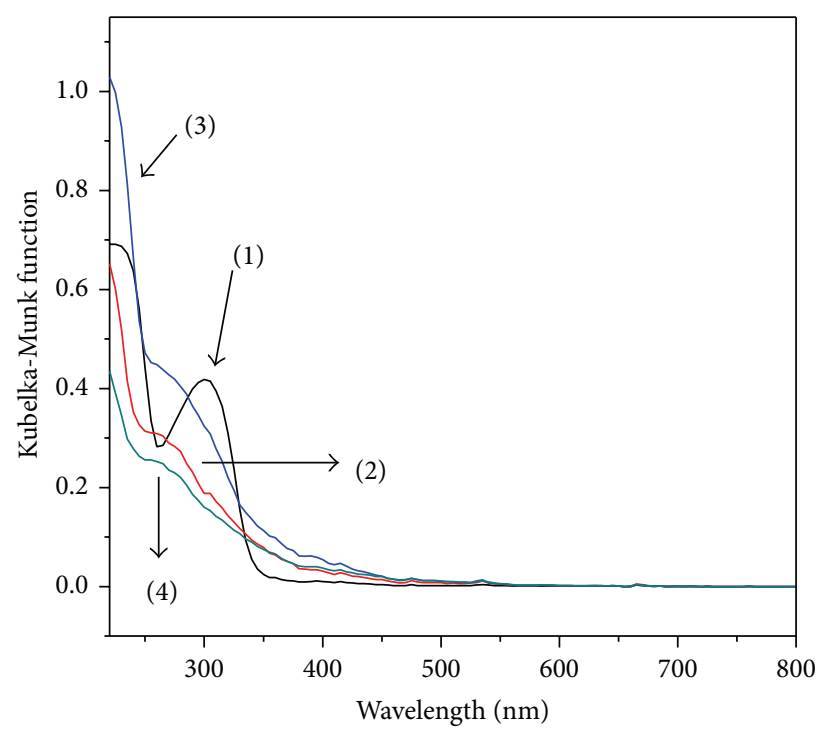

(1) Zn3Al-LDH

(2) Zn3Al-LDH-SDS $0.2 \mathrm{M}$

(3) Zn3Al-LDH-SDS $0.4 \mathrm{M}$ (4) Zn3Al-LDH-SDS $0.8 \mathrm{M}$

(b)

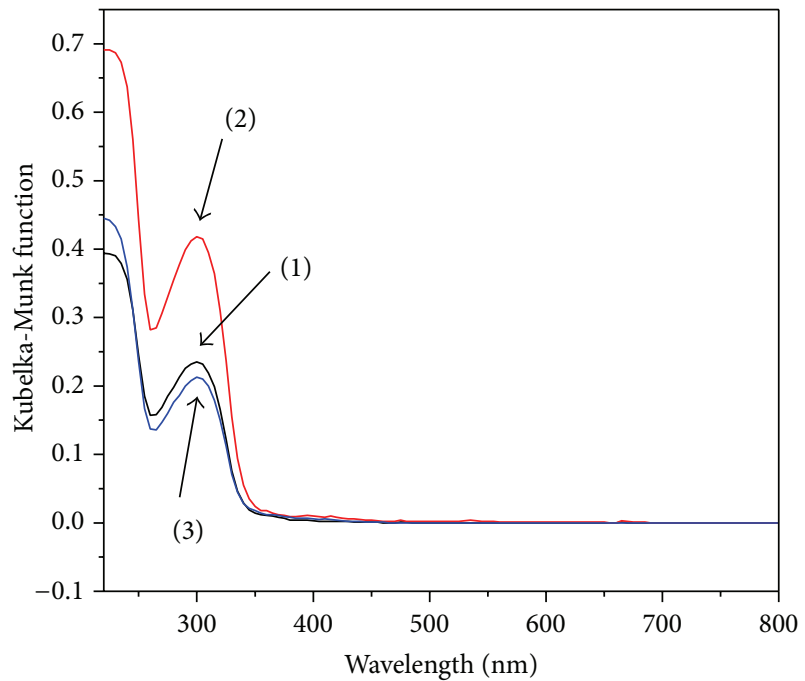

(1) Zn2Al-LDH
- (2) Zn3Al-LDH
- (3) Zn4Al-LDH

(c)

(3) Zn4Al-LDH-SDS $0.4 \mathrm{M}$

(4) Zn4Al-LDH-SDS $0.8 \mathrm{M}$

(d)

FIGURE 6: Diffuse reflectance UV-visible absorption spectra of $\mathrm{Zn} r \mathrm{Al}-\mathrm{NO}_{3}-\mathrm{LDH}$ and LDH-SDS in different concentrations.

the different prepared samples were tabulated in Table 2. $E_{g 1}$ and $E_{g 2}$ can be attributed to the presence of $\mathrm{NO}_{3}{ }^{-}$groups in the LDH interlayer [10]. In addition, $E_{g 1}$ also can be ascribed to the electronic transition of $\mathrm{Zn}-\mathrm{Al}-\mathrm{LDH}$ which is a direct process from oxygen $2 p$ to metal $n s$ or $n p$ levels $(n=4$ for $\mathrm{Zn}$ and $n=3$ for Al) [17]. These results are in good agreement with the literature [14]. The peak corresponding to the $\mathrm{NO}_{3}{ }^{-}$ radical at $300 \mathrm{~nm}$ in Figure 6 confirms this suggestion.

Due to the intercalation of SDS into the LDH interlayer, SDS is replaced with $\mathrm{NO}_{3}{ }^{-}$in the interlayer galleries. Consequently, for $\mathrm{Zn} r \mathrm{Al}-\mathrm{LDH}$-SDS samples in different concentration of SDS, for $r=2$, the band gap energy of $E_{g 1}$ and $E_{g 2}$ is found to increase to $5.2 \mathrm{eV}$ and $4.1 \mathrm{eV}$, respectively, and for $r=3, E_{g 1}$ and $E_{g 2}$ increased to around $5.1 \mathrm{eV}$ and $3.9 \mathrm{eV}$, respectively. These $E_{g}$ values can be due to the electronic transition of the oxygen from the DS anion $\left(\mathrm{SO}_{4}{ }^{2-}\right)$ and a nearby $\mathrm{Al}$ nucleus $(I=5 / 2)$ from the LDH sheets. When $r=4$, for sample with $0.2 \mathrm{M}$ of SDS, the values of $E_{q 1}$ and $E_{g 2}$ were found around $4.3 \mathrm{eV}$ and $3.2 \mathrm{eV}$, respectively, while, for $0.4 \mathrm{M}$ and $0.8 \mathrm{M}$ of SDS, only one energy gap in $3.2 \mathrm{eV}$ was observed.

Figure 6 shows the diffuse reflectance UV-visible absorption spectra of different samples, which exhibits a clear peak at $300 \mathrm{~nm}$ for $\mathrm{LDH}$ samples corresponding to the existence 
TABLE 1: The indexing and lattice parameters $\left(a, c\right.$, and $\left.c^{\prime}\right)$ of the PXRD for the ZnrAl-LDH and LDH-SDS with different concentration of SDS.

\begin{tabular}{|c|c|c|c|c|c|}
\hline Parameter $(\mathrm{nm})$ & $a$ & $c$ & $c^{\prime}$ & Interlayer thickness $^{\mathrm{a}}$ & $D^{\mathrm{b}}$ \\
\hline Zn2-Al-LDH & 0.30 & 2.64 & 0.88 & 0.40 & 30.29 \\
\hline LDH-SDS $0.2 \mathrm{M}$ & 0.30 & 7.67 & 2.55 & 2.07 & 29.99 \\
\hline LDH-SDS $0.4 \mathrm{M}$ & 0.30 & 7.74 & 2.58 & 2.10 & 42.89 \\
\hline LDH-SDS $0.8 \mathrm{M}$ & 0.30 & 7.78 & 2.59 & 2.11 & 51.44 \\
\hline Zn3-Al-LDH & 0.30 & 2.65 & 0.88 & 0.40 & 23.67 \\
\hline LDH-SDS $0.2 \mathrm{M}$ & 0.30 & 7.81 & 2.60 & 2.12 & 45.97 \\
\hline LDH-SDS $0.4 \mathrm{M}$ & 0.30 & 7.66 & 2.55 & 2.07 & 28.07 \\
\hline LDH-SDS $0.8 \mathrm{M}$ & 0.30 & 7.76 & 2.58 & 2.10 & 34.38 \\
\hline Zn4-Al-LDH & 0.30 & 2.66 & 0.88 & 0.40 & 28.85 \\
\hline LDH-SDS $0.2 \mathrm{M}$ & 0.30 & 7.69 & 2.56 & 2.08 & 23.42 \\
\hline LDH-SDS $0.4 \mathrm{M}$ & 0.30 & 7.84 & 2.65 & 2.12 & 31.57 \\
\hline LDHS-DS $0.8 \mathrm{M}$ & 0.30 & 7.73 & 2.57 & 2.09 & 33.09 \\
\hline
\end{tabular}

${ }^{\mathrm{a}}$ Interlayer thickness $=\left(c^{\prime}\right.$-brucite-like sheet thickness $)$.

${ }^{\mathrm{b}} D$ (average crystallite size in $c$ direction) = value calculated from the values of (003), (006), and (009) diffraction peaks using the Scherrer equation.

TABLE 2: The energy gaps of $\mathrm{Zn} r \mathrm{Al}-\mathrm{NO}_{3}-\mathrm{LDH}$ and LDH-SDS in different concentrations of SDS.

\begin{tabular}{lcc}
\hline Sample & $\begin{array}{c}E_{g 2} \\
(\mathrm{eV})\end{array}$ & $\begin{array}{c}E_{g 1} \\
(\mathrm{eV})\end{array}$ \\
\hline Zn2Al-LDH & 3.75 & 4.80 \\
Zn2Al-LDH-SDS 0.2 M & 4.10 & 5.20 \\
Zn2Al-LDH-SDS 0.4 M & 4.10 & 5.20 \\
Zn2Al-LDH-SDS 0.8 M & 4.15 & 5.20 \\
Zn3Al-LDH & 3.72 & 4.75 \\
Zn3Al-LDH-SDS 0.2 M & 3.90 & 5.10 \\
Zn3Al-LDH-SDS 0.4 M & 3.75 & 4.95 \\
Zn3Al-LDH-SDS 0.8 M & 3.90 & 5.10 \\
Zn4Al-LDH & 3.75 & 4.80 \\
Zn4Al-LDH-SDS 0.2 M & 3.20 & 4.30 \\
Zn4Al-LDH-SDS 0.4 M & 3.23 & - \\
Zn4Al-LDH-SDS 0.8 M & 3.24 & - \\
\hline
\end{tabular}

of $\mathrm{NO}_{3}{ }^{-}$ions in $\mathrm{LDH}$ interlayer [14]. The relative intensity of $300 \mathrm{~nm}$ peak for $\mathrm{Zn} 3 \mathrm{Al}-\mathrm{LDH}$ is higher than that of ratios 2 and 4 which suggests the increase in the crystallinity of $\mathrm{LDH}$ at ratio 3. For LDH-SDS samples with molar ratios 2 and 3, the absorption peaks at around $265 \mathrm{~nm}$ are assigned to the $\mathrm{SO}_{4}{ }^{2-}$ nanostructures formed within $\mathrm{LDH}$ samples due to the intercalation process. The broad peaks at around $355 \mathrm{~nm}$ for LDH-SDS samples with ratio 4 may suggest that they include more than an absorption peak with different degree of crystallinity due to the presence of $\mathrm{CO}_{3}{ }^{2-}$ anions (as was observed in FTIR) and $\mathrm{SO}_{4}{ }^{2-}$ phase.

3.4. Thermal Diffusivity. One of greatest importance thermal properties which is used to study the conductive heat of materials is thermal diffusivity $(\alpha)$. Equation (3) displays the dependency of thermal diffusivity to physical properties
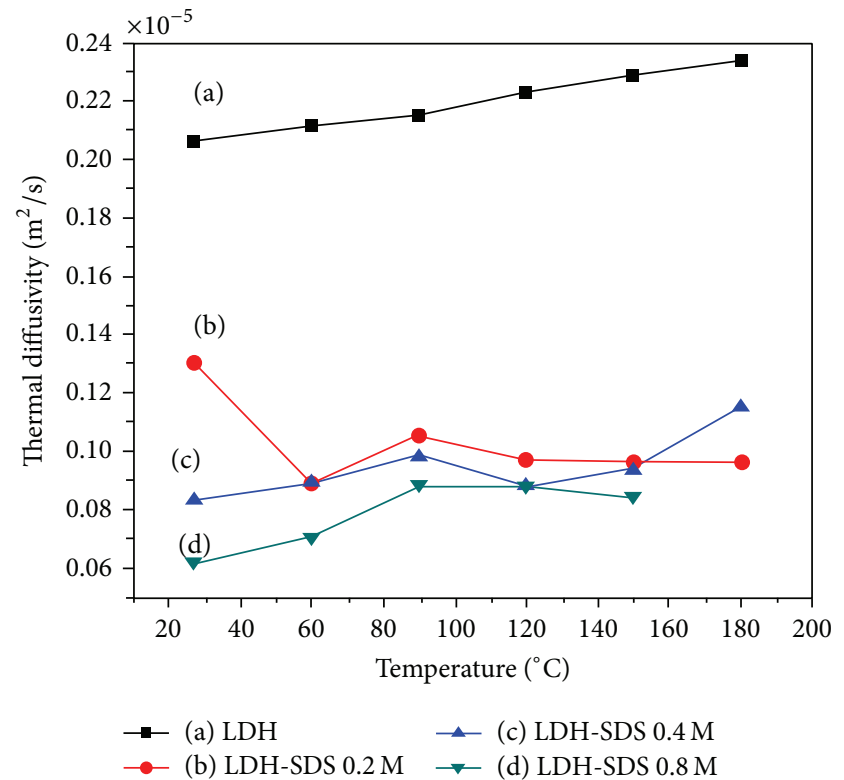

FIGURE 7: In situ temperature versus thermal diffusivity for Zn4AlLDH and LDH-SDS in different concentrations of SDS.

such as specific heat capacity $\left(c_{p}\right)$, density $(\rho)$, and thermal conductivity $(k)$

$$
\alpha=\frac{k}{\rho} c_{p} .
$$

A nonlinear relation of thermal diffusivity versus in situ temperatures for $\mathrm{Zn} 4 \mathrm{Al}-\mathrm{LDH}$ and $\mathrm{LDH}-\mathrm{SDS}$ in different concentration of SDS is shown in Figure 7. The results display that the thermal diffusivity of pure $\mathrm{LDH}$ is increasing as the temperature increases. Thermal diffusivity of LDHSDS samples were decreased compared to $\mathrm{Zn} / \mathrm{Al}-\mathrm{LDH}$. The results explain that the value of thermal diffusivity was also decreased as the amount of SDS increased at room temperature. By increasing the temperature typically it was 


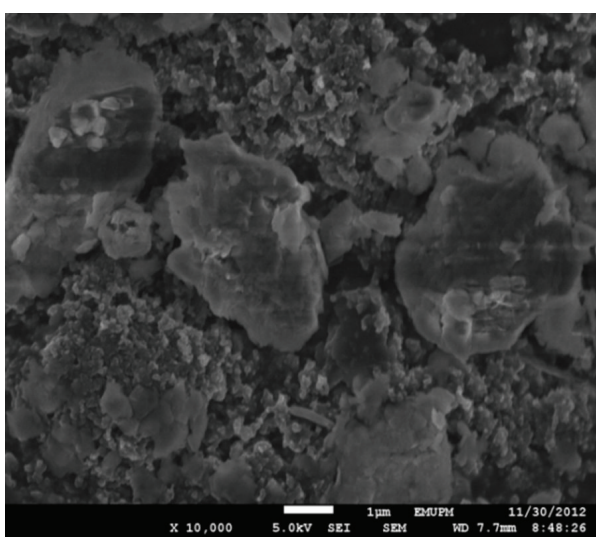

(a)

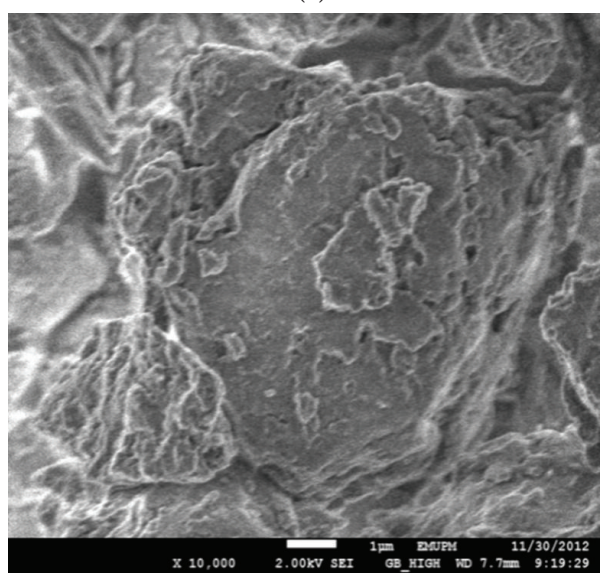

(c)

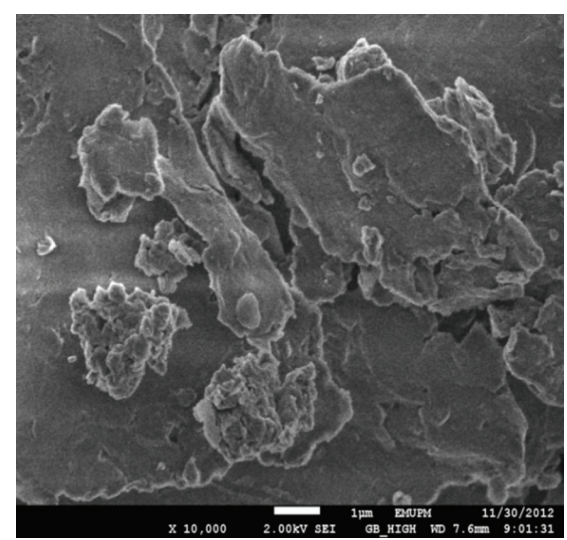

(b)

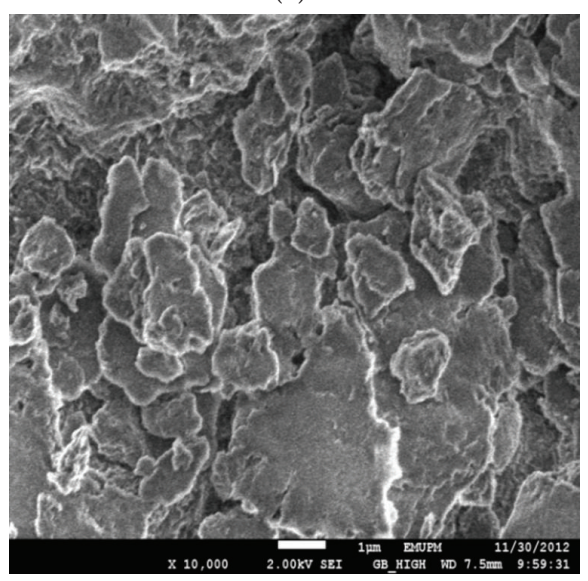

(d)

Figure 8: FESEM images of Zn4Al-LDH synthesized in the presence of (a) no SDS, (b) 0.2 M SDS, (c) 0.4 M SDS, and (d) 0.8 M SDS.

observed to increase up to $90^{\circ} \mathrm{C}$ and decrease up to the higher temperature.

3.5. Field Emission Scanning Electron Microscopy (FESEM). The FESEM micrographs of $\mathrm{Zn} / \mathrm{Al}-\mathrm{NO}_{3}-\mathrm{LDH}$ and $\mathrm{Zn} / \mathrm{Al}-$ $\mathrm{LDH}-\mathrm{SDS}$ samples prepared at $\mathrm{Zn}^{2+} / \mathrm{Al}^{3+}$ molar ratio of 4 are shown in Figure 8.

The LDH sample shows darkness micrograph with rough texture some smooth regions and plate-like particles with roughly hexagonal shapes which indicate presynthesized LDH sheets. Observation of some flakes and rod-like structures on the surface for LDH-SDS sample identifies the new phase. It is also clear that by increasing the amount of SDS the flakes and rod-like structures increased on surface. The FESEM images of LDH-SDS samples revealed that they show agglomerates of compact and nonporous plate-like structures, not much different from the observed structure for $\mathrm{LDH}$, and there is no significant difference in the morphology of all samples. It is also very similar to the morphology of other nanocomposites, such as Zn-Al-poly(acrylic acid)-LDH, Zn-Al-poly(vinyl sulfonate)-LDH, and Zn-Alpoly(styrene sulfonate)-LDH [18].

\section{Conclusion}

$\mathrm{Zn} / \mathrm{Al}-\mathrm{LDH}-\mathrm{SDS}$ nanocomposites of different concentration of SDS have been prepared using a coprecipitation method.
The XRD and FTIR data show the successful intercalation of SDS into the LDH interlayer. The crystallinity of the LDHSDS nanocomposites increases by increasing the amount of SDS. The energy band gap of LDH-SDS samples was found to increase with respect to the unmodified $\mathrm{LDH}$. Thermal diffusivity was observed to decrease in the form of LDH-SDS nanocomposite.

\section{Conflict of Interests}

The authors declare that there is no conflict of interests regarding the publication of this paper.

\section{Acknowledgment}

The authors would like to thank Universiti Putra Malaysia (UPM) for supporting this work.

\section{References}

[1] M. Y. Ghotbi, Synthesis, modification and characterization of layered Hydroxides and magnetite and their nanohybrids with dGluconate and gallate anions [M.S. thesis], Institute of Advanced Technology, 2009.

[2] M. Z. B. Hussein, A. H. Yahaya, M. Shamsul, H. M. Salleh, T. Yap, and J. Kiu, "Acid fuchsin-interleaved Mg-Al-layered double 
hydroxide for the formation of an organic-inorganic hybrid nanocomposite," Materials Letters, vol. 58, no. 3-4, pp. 329-332, 2004.

[3] E. M. Seftel, E. Popovici, M. Mertens et al., "Zn-Al layered double hydroxides: synthesis, characterization and photocatalytic application," Microporous and Mesoporous Materials, vol. 113, no. 1-3, pp. 296-304, 2008.

[4] A. A. Ali Ahmed, Z. Abidin Talib, and M. Z. B. Hussein, "ESR spectra and thermal diffusivity of $\mathrm{ZnAl}$ layered double hydroxide," Journal of Physics and Chemistry of Solids, vol. 73, no. 1, pp. 124-128, 2012.

[5] M. Z. B. Hussein and T. K. Hwa, "Synthesis and properties of layered organic-inorganic hybrid material: $\mathrm{Zn}-\mathrm{Al}$ layered double hydroxide-dioctyl sulfosuccinate nanocomposite," Journal of Nanoparticle Research, vol. 2, no. 3, pp. 293-298, 2000.

[6] L. Moyo, W. W. Focke, F. J. W. J. Labuschagne, and S. Verryn, "Layered double hydroxide intercalated with sodium dodecyl sulfate," Molecular Crystals and Liquid Crystals, vol. 555, pp. 5164, 2012.

[7] Y. Feng, D. Li, Y. Wang, D. G. Evans, and X. Duan, "Synthesis and characterization of a UV absorbent-intercalated Zn-Al layered double hydroxide," Polymer Degradation and Stability, vol. 91, no. 4, pp. 789-794, 2006.

[8] K. M. Parida, M. Sahoo, and S. Singha, "Synthesis and characterization of a Fe(III)-Schiff base complex in a Zn-Al LDH host for cyclohexane oxidation," Journal of Molecular Catalysis A: Chemical, vol. 329, no. 1-2, pp. 7-12, 2010.

[9] G. G. C. Arizaga, J. E. F. D. C. Gardolinski, W. H. Schreiner, and F. Wypych, "Intercalation of an oxalatooxoniobate complex into layered double hydroxide and layered zinc hydroxide nitrate," Journal of Colloid and Interface Science, vol. 330, no. 2, pp. 352358, 2009.

[10] H. Chai, X. Xu, Y. Lin, D. G. Evans, and D. Li, "Synthesis and UV absorption properties of 2,3-dihydroxynaphthalene-6sulfonate anion-intercalated $\mathrm{Zn}$-Al layered double hydroxides," Polymer Degradation and Stability, vol. 94, no. 4, pp. 744-749, 2009.

[11] J. Xu, D. Yan, S. Li, and J. Lu, "Controllable luminescence and electrochemical detection of $\mathrm{Pb}^{2+}$ ion based on the $2,2^{\prime}$ Azino-bis(3-ethylbenzothiazoline-6-sulfonate) dye and dodecanesulfonate co-intercalated layered double hydroxide," Dyes and Pigments, vol. 94, no. 1, pp. 74-80, 2012.

[12] M. Jitianu, M. Bãlãsoiu, R. Marchidan, M. Zaharescu, D. Crisan, and M. Craiu, "Thermal behaviour of hydrotalcite-like compounds: study of the resulting oxidic forms," International Journal of Inorganic Materials, vol. 2, no. 2-3, pp. 287-300, 2000.

[13] C. Yilmaz, U. Unal, and H. Yagci Acar, "Platelets to rings: influence of sodium dodecyl sulfate on $\mathrm{ZnAl}$ layered double hydroxide morphology," Journal of Solid State Chemistry, vol. 187, pp. 295-299, 2012.

[14] A. A. A. Ahmed, Z. A. Talib, M. Z. Bin Hussein, and A. Zakaria, "Zn-Al layered double hydroxide prepared at different molar ratios: preparation, characterization, optical and dielectric properties," Journal of Solid State Chemistry, vol. 191, pp. 271-278, 2012.

[15] A. A. A. Ahmed, Z. A. Talib, and M. Z. B. Hussein, "Thermal, optical and dielectric properties of $\mathrm{Zn}$-Al layered double hydroxide," Applied Clay Science, vol. 56, pp. 68-76, 2012.

[16] J. Torrent and V. Barron, "Diffuse reflectance spectroscopy of iron oxides," in Encyclopedia of Surface and Colloid Science, pp. 1438-1446, 2002.
[17] N. Ahmed, Y. Shibata, T. Taniguchi, and Y. Izumi, "Photocatalytic conversion of carbon dioxide into methanol using zinc-copper-M(III) ( $\mathrm{M}$ = aluminum, gallium) layered double hydroxides," Journal of Catalysis, vol. 279, no. 1, pp. 123-135, 2011.

[18] M. Z. B. Hussein, T.-Y. Yun-Hin, M. M. B. Tawang, and R. Shahadan, "Thermal degradation of (zinc-aluminium-layered double hydroxide-dioctyl sulphosuccinate) nanocomposite," Materials Chemistry and Physics, vol. 74, no. 3, pp. 265-271, 2002. 

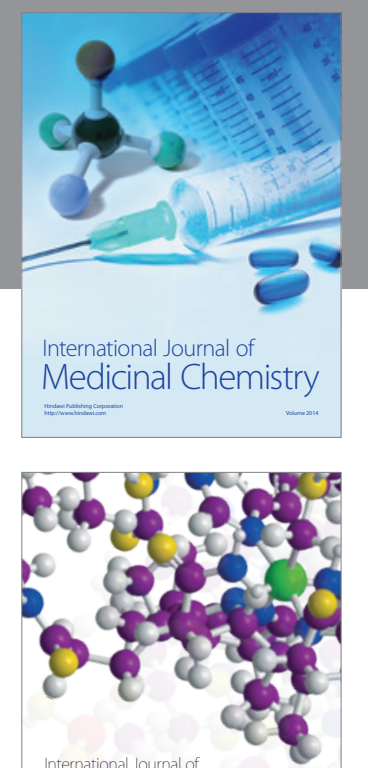

\section{Carbohydrate} Chemistry

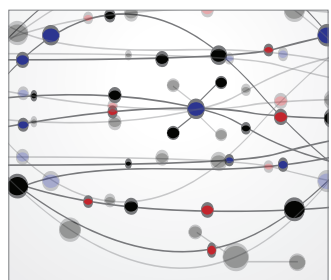

The Scientific World Journal
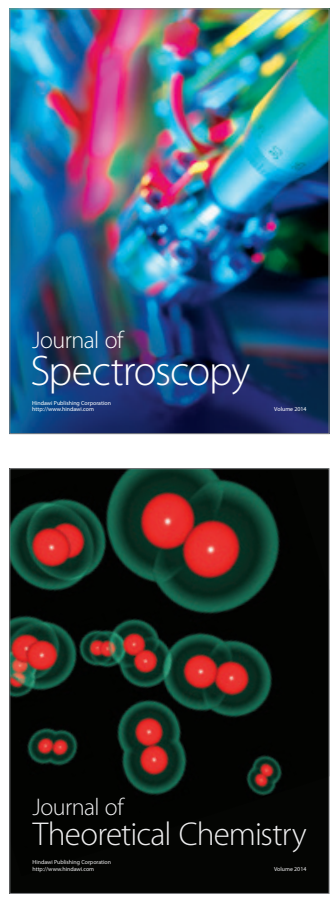
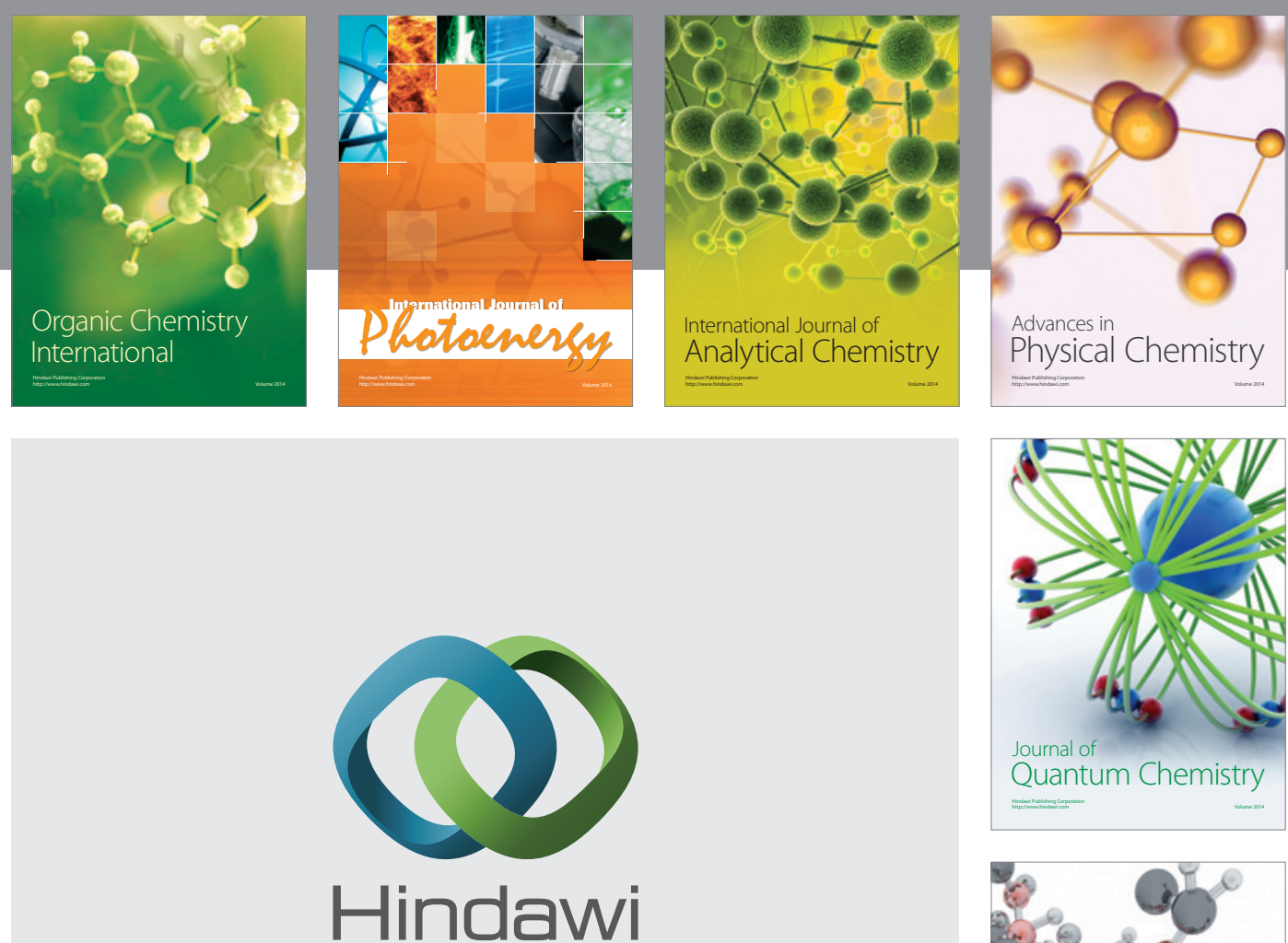

Submit your manuscripts at

http://www.hindawi.com

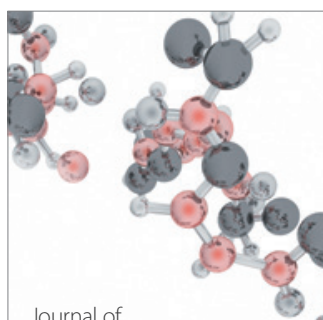

Analytical Methods

in Chemistry

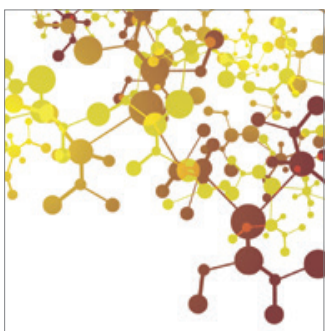

Journal of

Applied Chemistry

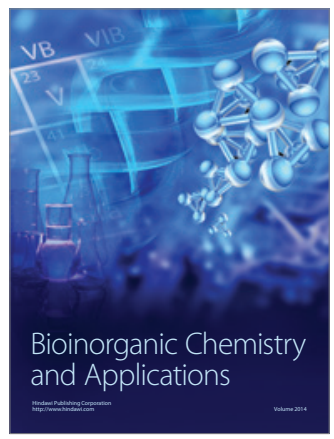

Inorganic Chemistry
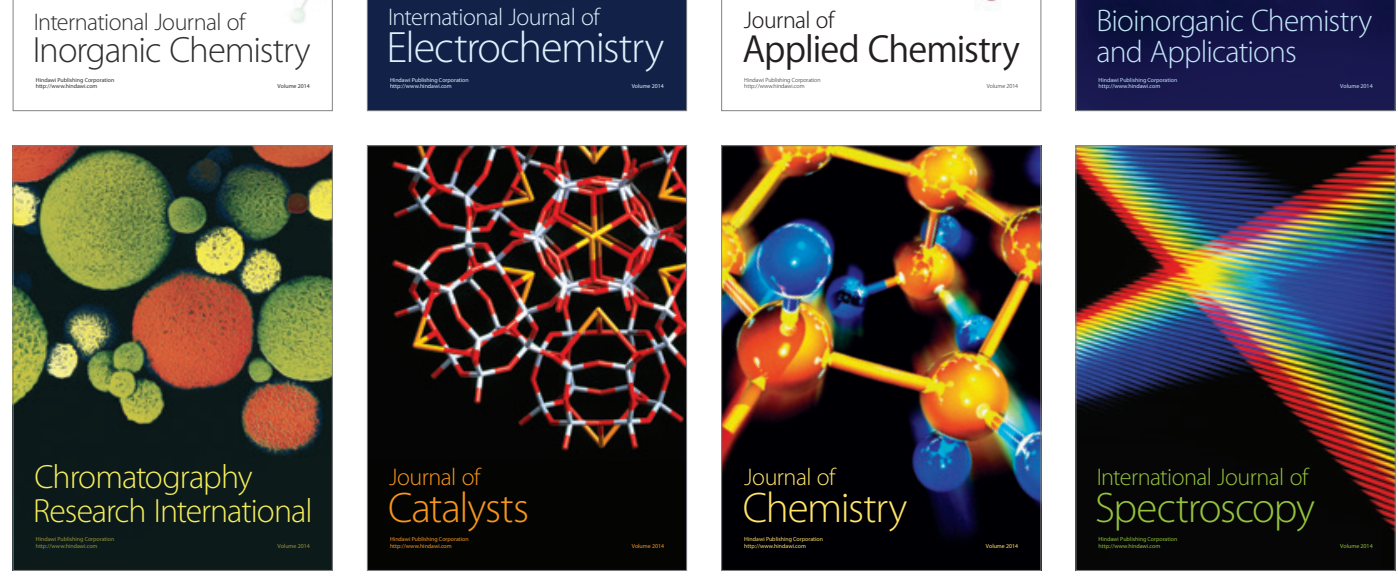